\title{
Able or unable to work? Life Trajectory after severe occupational Injury.
}

\author{
Jarna Kulmala 1, Arto Luoma 2, Lasse Koskinen 3
}

1 Faculty of Management, University of Tampere, Tampere, Finland

2 Faculty of Mathematics and Science, University of Jyväskylä, Jyväskylä, Finland

3 Faculty of Management, University of Tampere, Tampere, Finland

\begin{abstract}
Purpose To study the probabilities and permanence of return to work, inability to work and rehabilitation, and to explore the connection between these life situations and later working after a severe occupational injury.
\end{abstract}

Materials and Methods A historical cohort of Finnish workers with a severe occupational injury during 2008 ( $\mathrm{N}=11585)$ were followed up annually on the outcomes of return to work over a 5-year observation period. We examined transition probabilities from one life situation to another with Markov chain analysis, and applied logistic regression with generalized estimating equations to assess the effect of register-based determinants on return to work. Results Within the five anniversaries, $85 \%$ of the injured were working, $9 \%$ were unable to work (fully or partly) and 2\% received rehabilitation. Age, gross annual income, type of work, injured body part, injury type and the injured's annual condition subsequent to the occupational injury were significant determinants of return to work.

Conclusions The probability of return to work decreased with time, but, on average, one fifth of the injured workers succeeded in return to work after being unable to work on the previous anniversary, which indicates that it is worthwhile to conduct efforts for this target group in order to promote return to work.

Keywords: Return to work, Work disability, Rehabilitation, Occupational injuries 


\section{Introduction}

In 2015, Finnish wage earners experienced altogether 117908 occupational injuries, of which about $7 \%$ were severe injuries causing over 30 days off work [1]. In Finland, all wage earners are insured according to the Occupational Accidents, Injuries and Diseases Act, which defines the content of the statutory insurance cover. As a compensation for the loss of income, the injured worker is entitled to a daily allowance for 360 days from the day following the injury, and if the disability continues after this, the injured worker is entitled to an injury pension. The injury pension is paid as long as the injured is disabled due to the occupational injury, so the compensation can be lifelong. The disability can also be partial, in which case the daily allowance or the pension reflects the diminished ability to work. The entitlement to compensation requires a minimum of $10 \%$ reduction in the ability to work.

In addition, the insurance compensations for the loss of income include a rehabilitation allowance, which is paid during occupational rehabilitation. The occupational rehabilitation includes for example guidance and counselling, work trials in the previous or new job, supplementing occupational skills and training, which leads to an occupation. It can also include support for starting or continuing a business. The rehabilitation allowance is equivalent to the disability allowance or disability pension. One major objective of the Workers' Compensation system is to restore the worker's ability to return to work after the injury. Return to work is important not only to injured workers, but also to their employers and in a broad sense to the whole society.

Medical studies related to return to work do not usually distinguish between injuries and illnesses [2]. However, it may be important to acknowledge some crucial differences between them. Injuries clearly differ from illnesses when considering the recovery process and 
improvement in the ability to function. The majority of chronic illnesses tend to be slowly emerging with a gradual decline of functional ability. Due to this progressive nature of most illnesses, the essential resource factors necessary for secondary prevention and rehabilitation, such as self-esteem, well-being and economic situation, often slowly deteriorate resulting in a poor ability to function in the future. In contrast to illnesses, workers experiencing a severe injury will suffer from a sudden decline in the ability to function, and the above-mentioned essential resource factors are not usually weakened before the injury. In addition, because of natural healing, medical treatment and rehabilitation, the ability to function will only improve over time.

Although the majority of the studies within the subject area focus on illness or sickness absence, a reasonable number of them have examined return to work after an injury [see 3-5]. However, work-related and non-work related injuries can differ from each other when it comes to the return to work process and outcomes. In Finland, for example, there are relevant differences concerning the benefit system and stakeholders involved when comparing workrelated and non-work-related injuries [6]. Few studies have concentrated purely on workrelated injuries in the past [see 7-11, 27]. These studies have identified a substantial number of determinants of return to work outcomes, including socio-demographic, clinical, economic and psychological factors. The results indicate that younger age, higher education, higher preinjury income, good health status, higher job satisfaction, solid social and economic support and minor injury severity promote return to work. [2-3, 7-10].

The permanence of return to work and post-injury employment patterns have also been in the interest of researchers. The results suggest that a vast majority resume working after the injury [3, 5, 8]. However, return to work should not be considered purely as a single event, 
but rather as an evolving nonlinear process [11] with disability recurrences that are common after both injuries and illnesses. The majority (85-94\%) of injured workers had at least one return to work, but the rate of success significantly declined over a longer time span. [9, $12-$ 13].

Since the previous research has mainly focused on employment patterns, we lack sufficient information about the probabilities and permanence of other life situations such as full disability and rehabilitation. In addition, the fairly short follow-up periods (6 to 24 months) leave open questions about the longer-term post-injury life course. Furthermore, the research has not focused on severe occupational injuries before, even though these cases are the most important if we think about secondary prevention. The vast majority of all work injuries cause only 1-3 days off work requiring no specific efforts or intervention strategies, so the research attention should rather be targeted on severe injuries, where these efforts are mostly needed.

In order to improve secondary prevention, it is important to be aware of the probabilities, permanence and predictors of return to work, full disability and rehabilitation after a severe occupational injury. Comprehension of these life situations enables an optimal use and allocation of limited resources when rehabilitation and practices of targeted return to work are offered to those who benefit from them most.

This study examines the probabilities and permanence of return to work, full disability and rehabilitation after a severe occupational injury in Finland using register-based data including all injured workers with a severe occupational injury during 2008 (N=11585). The study focuses on five anniversaries following the injury. The specific objectives are as follows: (1) to examine the probabilities of return to work, full disability and rehabilitation after a severe occupational injury; (2) to investigate the permanence of these life situations and transitions 
between them; and (3) to study the connection between these life situations and working at a later stage.

\section{Materials and Methods}

\section{Data and Variables}

We used combined register-based data from the Finnish Workers' Compensation Centre and the Finnish Centre of Pensions. All cases of severe occupational injury that occurred in 2008 were collected from the Finnish Workers’ Compensation Centre’s register, and other registerbased data were combined with them. We classified an occupational injury as severe if it had caused over 30 consecutive days off work by the end of 2009. Both workplace and commuting injuries were included.

We excluded the injured who were not Finnish citizens because the national registers did not contain information about their life situations after the injury. We also excluded those who had experienced a previous occupational injury during 2006-2007 $(n=443)$ in order to avoid the distortion of results. Finally, we excluded those who had received an old age pension by the time of the severe occupational injury $(n=100)$ as most of them had worked part-time only and would have retired fully during the observation period. This left us with 11585 persons in the data. The register datasets were anonymized so that it was not possible to trace individuals.

The primary data included information about severe occupational injuries classified according to the European Statistics on Accidents at Work methodology (Eurostat 2013). The additional data sets included information about (1) all insurance compensations for medical care, loss of earnings, functional limitations, rehabilitation, death and other costs for the years 2008-2013; 
(2) all other occupational injuries within 2008-2013; (4) all social benefits and pensions received during 2008-2013, and (5) employed periods and yearly incomes of the respondents.

The data on return to work and the gross annual income were based on the Finnish Centre of Pensions' employment register, which includes all employment contracts in Finland. The used data included all employment periods of the injured during 2007-2013, and we classified an individual as working if an employment period was continuing on the anniversary of the injury, and he or she did not receive any social benefits from the Social Insurance Institution of Finland or from pension institutions at the same time. The gross annual income was indexed to the 2013 level using the wage-level index.

The data on working inability and rehabilitation were based on the Finnish Workers’ Compensation Centre’s register, which includes all insurance benefits paid due to an occupational injury in Finland. We classified an individual as fully unable to work if he or she received the daily allowance or the workers’ compensation pension. Hence, the category "fully unable to work" includes both the temporary and permanently disabled due to an occupational injury.

Those receiving the partial daily allowance or the partial workers' compensation pension were classified as partly unable to work. Again, this category includes both temporarily and permanently partly disabled due to an occupational injury. Further, those receiving the rehabilitation allowance on the anniversary of the occupational injury were classified as rehabilitees. In the Finnish statutory workers’ compensation insurance system, the rehabilitation allowance is paid during occupational rehabilitation, and includes compensation 
for the loss of income during the retraining period. The rehabilitation allowance is always temporary.

The data on unemployed, old-age pensioners and deceased were based on the registers of the Finnish Workers’ Compensation Centre. Those receiving the basic unemployment allowance, earnings-related unemployment allowance or labor market subsidy were classified as unemployed. Similarly, those receiving the old-age pension, early old-age pension, unemployment pension or part-time pension as old-age pensioners were classified as old-age pensioners.

The data on gender, age, occupation, geographical area of the injury, injured body part and the type of injury were also collected from the Finnish Workers' Compensation Centre's register. The age at the time of the severe occupational injury was grouped into three categories: 14 34, 35-49, and 50-68 years. The occupation was classified using the Finnish Workers' Compensation Centre’s earlier classification (2004), and a ten-class variable indicating the industry group was formed from the original three-digit occupation tags. The data on the injured body part and the type of injury were classified according to the European Statistics on Accidents at Work methodology [14].

\section{Statistical Analysis}

We used simple Markov chain analysis to examine the probabilities of different life situations and transitions between them during the five-year observation period. Markov chains describe transitions between different states by assuming that the probabilities of different states only depend on the previous state. In this study we examined five life situations (states): (1) 
working; (2) fully unable to work; (3) partly unable to work; (4) rehabilitation and (5) other situation.

The effect of the previous life situation (subsequent to injury) and other determinants of return to work were investigated with a logistic regression analysis that included the values of the dependent variable on the four latest anniversaries. However, since the values of the same individual are positively correlated, and an analysis ignoring this might result to overly significant outcomes, we applied the generalized estimation equations method in combination with the logistic link. This method enables defining various correlation structures between observations. We used the exchangeable correlation structure, which allows for betweenindividual variation in the mean level of the response variable. However, the estimator and its covariance matrix would be consistent, even if the correlation structure were incorrectly specified [15]. The analysis was implemented using the library "geepack" of the R software [16-17].

\section{Results}

Table 1 summarizes the (proportional) frequencies of working, inability to work, rehabilitation, unemployment, old age pension and death on the five anniversaries of the severe occupational injury. The category “other situation” includes for example the students, those in parental leave and the disabled due to a reason other than a severe occupational injury.

Table 1 here

The majority of the injured were working on the anniversaries (59-71\%), although the number of workers decreased steadily over time. A closer examination revealed that the 
decrease was mainly due to the retirement of the injured. As the table shows, the proportion of old-age pensioners grows steadily during the years, and in the fifth anniversary, $13 \%$ of the injured were old-age pensioners. Only $6 \%$ of the injured $(n=677)$ were fully unable to work due to the occupational injury on the first anniversary. The number of those fully unable to work decreased annually so that only $2 \%$ of the injured $(n=203)$ were disabled on the fifth anniversary.

On the contrary, the number of those who were partly unable to work due to the occupational injury slightly increased with time but remained at a low level of 23-52 individuals throughout the observation period. The number of rehabilitees varied between 38 and 109 individuals or $0.4-1.0 \%$ of the injured. The unemployment rate of the injured remained near $10 \%$ throughout the observation period. This rate is slightly higher than the overall unemployment rate in Finland during the same period, but without proper reference data for comparisons it is not possible to make conclusions about the relationship between severe occupational accidents and unemployment.

The permanence of different life situations and the transition probabilities between them were studied using simple Markov chain analysis. The following five categories were used for outcomes: "working”, "fully unable to work (due to occupational injury)”, "partly unable to work (due to occupational injury)”, “injury rehabilitation” and “other situation”. Here, the category "other situations" includes for example the unemployed and deceased persons, oldage pensioners, students and disabled due to a reason other than a severe occupational injury.

Table 2 consists of four components, all of which provide the transition probabilities between the life situations on two consecutive anniversaries. A successful return to work predicted 
continued working for the majority of injured. Over $84 \%$ of those working on any anniversary were also doing so after one year. Moreover, most transitions from state "working” occurred to state “another life situation”, which in most cases indicates retirement, unemployment or disability due to reasons not related to the occupational injury. Only a small fraction of the injured transferred from state "working" to state "fully unable to work due to the occupational injury”.

The inability to work was not as permanent life situation as working during the first three anniversaries. The transition probability from "fully unable to work" to "working” was $28.8 \%$ between the first and the second anniversaries. However, this probability decreased over time to be $10.1-18.6 \%$ between the subsequent anniversaries. In addition, about one tenth of those who were disabled on one of the first three anniversaries moved to rehabilitation during the next year (7.9-10.6\%). All in all, the transition probabilities from disability to other life situations decreased with time, and the majority of individuals who were fully unable to work on one anniversary also remained so on the next anniversary (35.7-77.2\%).

A fairly similar development of transition probabilities could be detected among those who were partly unable to work on the first anniversary of the severe occupational injury. The transition probability from partial disability to working was $43.5 \%$ between the first and the second anniversary, but significantly decreased after this. Hence, partial inability to work became a more permanent life situation with time, so that $81.6 \%$ of those who were partly unable to work on the fourth anniversary were in the same situation also after one year.

Rehabilitation appeared as a fairly permanent life situation as well; the majority (59-71\%) of the rehabilitees on any anniversary were also in rehabilitation after one year. The second largest transition probability was from rehabilitation to full inability to work, varying between 
13.2 and $20 \%$ on different anniversaries. Return to work after rehabilitation was low; only 4 $6 \%$ of the rehabilitees were working on the following anniversary. The high stability of the "other life situation" is mainly due to the old age pensioners and dead individuals, who were classified into this category. Thus, transition probabilities from “other life situation” to working, disability or rehabilitation are modest throughout the anniversaries and only decrease over time.

The unemployed are the largest subgroup in "other situation" who transition to working. An additional analysis showed that approximately one fourth of those unemployed on one anniversary were working on the next. However, at the same time the permanence of unemployment seemed quite high, so that over $50 \%$ of those who were unemployed on one anniversary were so also after one year. The analysis also showed that there were no transitions from unemployment to disability or rehabilitation due to a severe occupational injury.

Table 2 here

Associations between the explanatory variables and working were analyzed using a logistic regression model that included the working status on the four latest anniversaries as the dependent variable. The variables age, gross annual income, type of work, injured body part, injury type and life situation on the previous anniversary had a statistically significant association with working, and were therefore chosen for the final analysis. In agreement with earlier research, gender was excluded because it was not a statistically significant determinant of return to work $[8,12]$. Table 3 shows the distributions of the explanatory variables and their associations with working on the four latest anniversaries. 
Younger age and higher gross annual income were associated with increased working $(\mathrm{p}<0.001)$. In addition, working was more probable among non-manual employees (technical, scientific, legal, humanistic and artistic work) than among manual workers (mining, quarrying and construction work). Further, those whose injuries were in the upper and the lower extremities had the highest probabilities of working, while those with injuries in the neck or the head had the lowest probabilities. Although the differences between the injury types were small, bone fractures, wounds and superficial injuries were associated with higher probabilities of working whereas concussions and internal injuries were associated with lower probabilities.

In agreement with the Markov chain analysis, the life situation on one anniversary was a strong predictor of working in the future. The odds of working on a specific anniversary were 15.15 times greater for an individual who had worked on the previous anniversary than for an individual who had been fully unable to work. However, the odds of working were greater for those who had been fully unable to work on the previous anniversary than for those who had been partly unable to work, in rehabilitation or in another life situation.

We also investigated whether an additional occupational injury after the primary occupational injury had an effect on the later working outcomes.

The GEE analysis indicated that mild occupational injuries (causing less than 30 days off work) were actually related to better chances of working in the future. This result can be explained by the general employment situation of the injured, which would affect both the working status on the anniversary and the probability of a new injury. However, when considering additional severe occupational injuries, the result was no more statistically 
significant. Such an injury would reflect a good employment situation, but, on the other hand, would also reduce the chances of working in the future. Hence, in the GEE analysis these effects offset one another. Because of a confounding factor, the general employment situation, we did not include the variable “additional occupational injuries” in the final GEE model.

Table 3 here

\section{Discussion}

In Finland, there are over 10000 severe occupational injuries causing over 30 days off work every year. We examined the probabilities and permanence of return to work, inability to work and rehabilitation after a severe occupational injury over a follow-up period of 5 years. Overall, $85 \%$ of the injured were working during the five anniversaries of the injury, which is in line with the previous results that vary from $29 \%$ to $100 \%$, with a median of $71 \%$ for workrelated injuries [18].

However, $85 \%$ is a relatively high rate considering that the target group consisted of workers with a severe injury causing over 30 days off work. The long follow-up period partly explains the high overall working rates. In addition, the proportion of those working on any particular anniversary was clearly lower, varying from 59 to $71 \%$ of the injured. A closer look revealed that retirement explains most of the declining proportion of workers during the follow-up.

Otherwise, the permanence of working was high. Over $84 \%$ of those who were working on one anniversary were doing so also on the next anniversary. The majority of those not working on the next anniversary had either retired or become unemployed. Thus, the ability to 
work was usually sustained in the long term after the first return to work. On average, less than $1 \%$ of those who worked on one anniversary were fully unable to work on the next one. Altogether, only few moved from the category "working” to "fully or partly unable to work" or "rehabilitation".

The female sex, blue collar occupation, higher age, afflictions involving the neck or multiple locations and poor employer accommodations have previously been reported as risk factors for the recurrence of work disability $(9,12,19)$. Return to work after a severe occupational injury can be a challenge to many injured workers. Apart from being alienated from working life as a result of a long absence period, the injured may feel anxious about the return especially if the injury happened in the workplace. Possible employer accommodations such as reduced hours, modified equipment and lighter workloads have proven effective in maintaining employment in the long term (12).

In our study, only $1.7 \%$ of the injured $(n=199)$ experienced a recurrence of disability during the five year observation period. The recurrence rate was clearly lower than in the previous studies, where it varies between 11 and 48\% [9, 19]. However, these results are not fully comparable with our study, since our analysis only involved the five anniversaries of the severe injury and ignored the life situation between these time points. Therefore, the recurrence rates could not be evaluated as accurately as in the previous studies. In addition, the majority of these studies focus on occupational illnesses whereas our interest lies purely in occupational injuries. As mentioned earlier, there are some crucial differences between injuries and illnesses, so return to work patterns in these cases may also differ. 
The proportion of those who were fully unable to work due to a severe occupational injury declined over the years from $6 \%$ to $2 \%$. These numbers are fairly low compared to the results from Australia, where in about $10 \%$ of the cases the claimant became fully unable to work for long periods of time or permanently [20]. Moreover, our study only included those who were injured in a severe occupational injury, and therefore, supposedly had a higher risk of longterm or permanent disability.

The longer the disability period, the less likely the injured worker will ever return to work [21]. This declining probability of return to work after a longer disability time was clearly seen in our results too. The return to work rate was $29 \%$ for those who were fully unable to work on the first anniversary, 18-19\% for those who were fully unable to work on the second or third anniversaries and $10 \%$ for those who were fully unable to work on the fourth anniversary. However, these return to work rates indicate that the probability of recovery is relatively high even for those with long-term disabilities. This minority of injured account for the majority of workers’ compensation costs [21], so our positive results of their return to work rates encourage to further develop intervention strategies and prevention measures of permanent disability.

The number of rehabilitees remained small (0-1\%) throughout the observation period, but the permanence was quite high as the majority of those who were in rehabilitation on one anniversary were so also after one year. Somewhat surprisingly, return to work after rehabilitation seemed very modest. Only $4-6 \%$ of the rehabilitees were working on the following anniversary after rehabilitation. Both the permanence of rehabilitation and low return to work rates are partly explained by the length of occupational rehabilitation measures. Further, a noticeable number of injured were fully or partly unable to work on the following anniversary after rehabilitation, which might be due to more challenging individual or 
occupational factors of those taken into rehabilitation. There is still a need for a more thorough investigation of this matter.

The results show that age, gross annual income, type of work, injured body part, injury type and the injured's annual life situation after the occupational injury were all significant determinants of a person being at work after a severe occupational injury. Overall, these determinants are fairly similar to those in previous studies concerning return to work after illness or injury [8-9, 12]. While earlier results concerning gender as a statistically significant predictor are somewhat inconsistent [22-23], we did not find a statistically significant association between it and the working status after a severe occupational accident.

Younger age, higher incomes and non-manual work were associated with better chances of working, which is consistent with most of earlier work [3, 8-9]. On the contrary, injuries involving the neck or head decreased the probability of working, as did concussions and internal injuries as types of injury. Fairly similar results have been reported by MacKenzie et al [22] and Berecki-Gisolf et al. [9].

As distinct from previous study designs, we also used the life situation of the previous anniversary as an explanatory variable for the working status. As expected, the odds of working were clearly highest for those who had worked on the previous anniversary. However, an interesting finding was that the odds for working were also fairly high for those who had been fully unable to work on the previous anniversary, at least when compared to those partly unable to work, in rehabilitation or in some other life situation.

\section{Strengths and Limitations}


Several studies have examined the predictors and patterns of return to work after a workrelated injury, but the results are somewhat inconsistent. The inconsistencies result from the differences in target population, selection criteria, study design, data analysis, prognostic factors and observation period among others [2, 24-25]. Our data were collected from reliable register-based sources and included all wage earners' severe occupational injuries that occurred in Finland in 2008. The follow-up period was relatively long extending to 5 years from the severe occupational injury. The return to work was determined by employment contracts, not by the termination of the insurance benefit, thus taking into account other possible life situations such as unemployment, retirement, studying and parental leave.

As for limitations, the used data enabled the examination of the life situation on the anniversaries of the accident, but the exact transition dates between the anniversaries remained unknown. Therefore, the overall picture of transition between working, inability to work, rehabilitation and other life situations was simplified. Furthermore, there was no information available regarding the stakeholders' (employers, coworkers, healthcare providers and workers' compensation insurers) activities and interactions, which have also been proved to affect the return to work outcomes [7, 26].

In addition, this study relied entirely on information from the national registers, so a range of important variables, such as social, clinical and psychological factors, that have turned out to be important to return to work $[3,8]$ were missing. For example, psychiatric conditions such as post-traumatic stress disorder (PTSD) have been reported as a result of a severe injury [27]. In Finland, the Workers' Compensation system is responsible for the stress reactions caused by an occupational injury, and the injured can receive a daily allowance or injury pension due to these conditions. Therefore, the injured suffering from psychiatric conditions caused by the occupational injury were included in the category "disabled due a severe occupational 
accident”. However, psychiatric conditions were not separated as types of injury in the original data. Hence, we were not able to study the effect of these conditions on return to work patterns.

\section{Conclusions}

This study confirms the results of the previous reports on factors associated with return to work after injuries and extends current knowledge about the permanence of return to work and about transitions between various life situations after a severe occupational injury. The most important implication of this study for disability management is the acknowledgment of the high chances of return to work also for those with longer-time disability. Hence, the promotion of return to work is highly recommended also for this target group. However, additional information is needed to explain the low probability of return to work after rehabilitation.

\section{Declaration of Interest}

The authors declare that they have no conflict of interest. 


\section{References}

1. Finnish Workers' Compensation Centre. Työtapaturmat - Tilastovuodet 2005-2015. [Occupational injuries - statistics 2005-2015]. Finnish. [cited 2017 Aug 17]. Available at: http://www.tvk.fi/tietopalvelu-ja-julkaisut/julkaisut/.

2. Krause N, Frank JW, Dasinger LK, Sullivan TJ, Sinclair SJ. Determinants of duration of disability and return to work after work related injury and illness: Challenges for future research. American journal of industrial medicine. 2001;40(4):464-484.

3. Lange C, Burgmer M, Braunheim M, Heuft G. Prospective analysis of factors associated with work reentry in patients with injury-related injuries. Journal of occupational rehabilitation. 2007;17(1):1-10.

4. Young A, Wasiak R, Roessler R, McPherson K, Anema J, van Poppel M. Return-towork outcomes following work disability: stakeholder motivations, interests and concerns. Journal of Occupational Rehabilitation. 2005;15(4):543-556.

5. Post, RB, Van Der Sluis, CK, Ten Duis, HJ. Return to work and quality of life in severely injured patients. Disability and rehabilitation. 2006:28(22):1399-1404.

6. EU. Your social security rights in Finland. European commission, Employment, Social Affairs \& Inclusion. 2013. [cited 2017 Aug 22]. Available at: http://ec.europa.eu/employment_social/empl_portal/SSRinEU/Your\%20social\%20sec urity\%20rights\%20in\%20Finland_en.pdf.

7. Kenny DT. Returning to work after workplace injury: Impact of worker and workplace factors. Journal of applied rehabilitation counseling. 1998;29(1): 13.

8. He Y, Hu J, Yu ITS, Gu W, Liang Y. Determinants of return to work after occupational injury. Journal of occupational rehabilitation. 2010;20(3):378-386.

9. Berecki-Gisolf J, Clay FJ, Collie A, McClure RJ. Predictors of sustained return to work after work-related injury or disease: insights from workers' compensation claims records. Journal of occupational rehabilitation. 2012;22(3):283-291.

10. Young AE. Return to work following disabling occupational injury-facilitators of employment continuation. Scandinavian journal of work, environment \& health. 2010;36(6):473-483.

11. Young, AE. An exploration of alternative methods for assessing return-to-work success following occupational injury. Disability and rehabilitation. 2014:(36)11: 914-924. 
12. Butler RJ, Johnson WG, Baldwin ML. Managing work disability - why $1^{\text {st }}$ return to work is not a measure of success. Ind Labor Relat rev. 1995;48(3):452-69.

13. Bültmann U, Franche RL, Hogg-Johnson S, Côté P, Lee H, Severin C, Vidmar M, Carnide N. Health status, work limitations, and return-to-work trajectories in injured workers with musculoskeletal disorders. Quality of Life Research. 2007;16(7):1167_ 1178.

14. Eurostat. European Statistics on Injurys at Work (ESAW) Methodology. Luxembourg: Eurostat. 2013.

15. Liang K-Y, Zeger SL. Longitudinal data analysis using generalized linear models. Biometrika, 1986;73:13-22.

16. R Core Team. R: A language and environment for statistical computing. R Foundation for Statistical Computing, Vienna, Austria. 2015. [cited 2017 Sep 19]. Available at: https://www.R-project.org/.

17. Højsgaard S, Halekoh U, Yan J. The R Package geepack for Generalized Estimating Equations. Journal of Statistical Software. 2006;15(2):1-11.

18. Athanasou JA. Return to work following whiplash and back injury: a review and evaluation. Medico-Legal Journal. 2005;73(1):29-33.

19. Wasiak R, Verma S, Pransky G, Webster B. Risk factors for recurrent episodes of care and work disability: case of low back pain. Journal of Occupational and Environmental Medicine. 2004;46(1):68-76.

20. RACP. Realising the health benefits of work. A Position Statement. The Australasian Faculty of Occupational and Environmental Medicine, The Royal Australasian College of Physicians (RACP). 2010.

21. Krause N, Dasinger LK, Neuhauser F. Modified work and return to work: A review of the literature. Journal of Occupational Rehabilitation. 1998;8(2):113-139.

22. MacKenzie EJ, Shapiro S, Smith RT, Siegel JH, Moody M, Pitt A. Factors influencing return to work following hospitalization for traumatic injury. Am J Public Health. 1987;77:329-34.

23. Ahlgren Å, Bergroth A, Ekholm J. Work resumption or not after rehabilitation? A descriptive study from six social insurance offices. International Journal of Rehabilitation Research. 2004;27(3):171-180.

24. Pransky G, Gatchel R, Linton SJ, Loisel P. Improving return to work research. Journal of occupational rehabilitation, 2005;15(4):453-457. 
25. Linton SJ, Gross D, Schultz IZ, Main C, Côté P, Pransky G, Johnson W. Prognosis and the identification of workers risking disability: research issues and directions for future research. Journal of Occupational Rehabilitation. 2005;15(4):459-474.

26. Franche RL, Krause N. Readiness for return to work following injury or illness: conceptualizing the interpersonal impact of health care, workplace, and insurance factors. Journal of occupational rehabilitation, 2002;12(4);233-256.

27. Lin KH, Guo NW, Shiao SC, Liao SC, Hu PY, Hsu JH., Hwang YH, Guo YL. The impact of psychological symptoms on return to work in workers after occupational injury. Journal of occupational rehabilitation. 2013;23(1):55-62. 
Table 1 Life situations of individuals following a severe occupational injury

\begin{tabular}{|c|c|c|c|c|c|}
\hline Life situation & $\begin{array}{l}\text { 1. anniversary } \\
\text { N (\%) }\end{array}$ & $\begin{array}{l}\text { 2. anniversary } \\
\text { N (\%) }\end{array}$ & $\begin{array}{l}\text { 3. anniversary } \\
\text { N (\%) }\end{array}$ & $\begin{array}{l}\text { 4. anniversary } \\
\text { N (\%) }\end{array}$ & $\begin{array}{c}\text { 5. anniversary } \\
\text { N (\%) }\end{array}$ \\
\hline working & 8168 (71) & 7788 (67) & $7526(65)$ & 7170 (62) & $6803(59)$ \\
\hline $\begin{array}{c}\text { fully unable to work } \\
\text { (due to occupational injury) }\end{array}$ & $677(6)$ & $352(3)$ & $279(2)$ & $228(2)$ & $203(2)$ \\
\hline $\begin{array}{c}\text { partly unable to work } \\
\text { (due to occupational injury) }\end{array}$ & $23(0)$ & $33(0)$ & $42(0)$ & $49(0)$ & $52(0)$ \\
\hline $\begin{array}{c}\text { rehabilitation } \\
\text { (due to occupational injury) }\end{array}$ & $38(0)$ & $105(1)$ & $109(1)$ & $101(1)$ & $71(1)$ \\
\hline unemployed & $1098(9,5)$ & $1290(11)$ & $1106(10)$ & 1109 (10) & $1171(10)$ \\
\hline old age pension & $300(3)$ & $558(5)$ & $847(7)$ & $1134(10)$ & 1447 (13) \\
\hline deceased & $66(1)$ & $111(1)$ & $149(1)$ & $186(2)$ & $235(2)$ \\
\hline other situation & 1215 (10) & $1348(12)$ & 1527 (13) & $1608(14)$ & 1603 (14) \\
\hline In total & 11585 (100) & 11585 (100) & $11585(100)$ & 11585 (100) & 11585 (100) \\
\hline
\end{tabular}


Table 2 Markov chain analysis of transition possibilities between consecutive anniversaries from one life situation to another

\begin{tabular}{|c|c|c|c|c|c|c|c|}
\hline \multirow{3}{*}{ 1. anniversary } & & \multicolumn{5}{|c|}{ 2. anniversary } & \multirow{3}{*}{$\begin{array}{c}\text { In total } \\
\%\end{array}$} \\
\hline & & & $\begin{array}{l}\text { fully unable } \\
\text { to work }\end{array}$ & $\begin{array}{l}\text { partly unable } \\
\text { to work }\end{array}$ & & $\begin{array}{c}\text { other } \\
\text { situation }\end{array}$ & \\
\hline & & $\%$ & $\%$ & $\%$ & $\%$ & $\%$ & \\
\hline working & $\%$ & 84.1 & 1.1 & 0.0 & 0 & 14.7 & 100 \\
\hline fully unable to work & $\%$ & 28.8 & 35.7 & 3.2 & 10.6 & 21.6 & 100 \\
\hline partly unable to work & $\%$ & 43.5 & 13.0 & 30.4 & 4.3 & 8.7 & 100 \\
\hline rehabilitation & $\%$ & 5.3 & 13.2 & 0.0 & 71.1 & 10.5 & 100 \\
\hline other situation & $\%$ & 26.5 & 0.5 & 0.1 & 0.1 & 72.8 & 100 \\
\hline
\end{tabular}

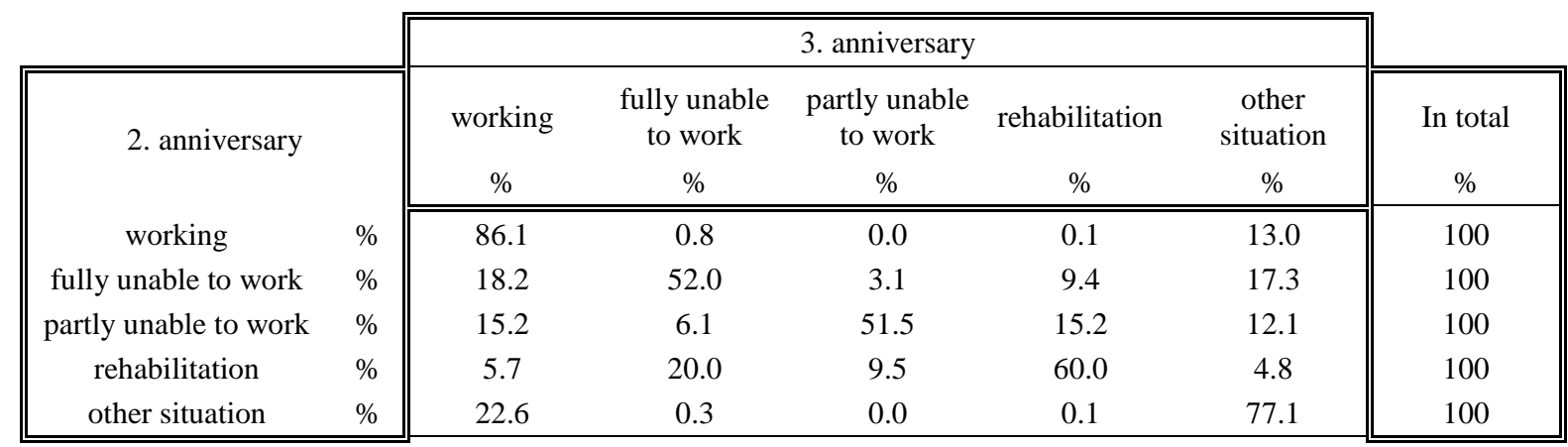

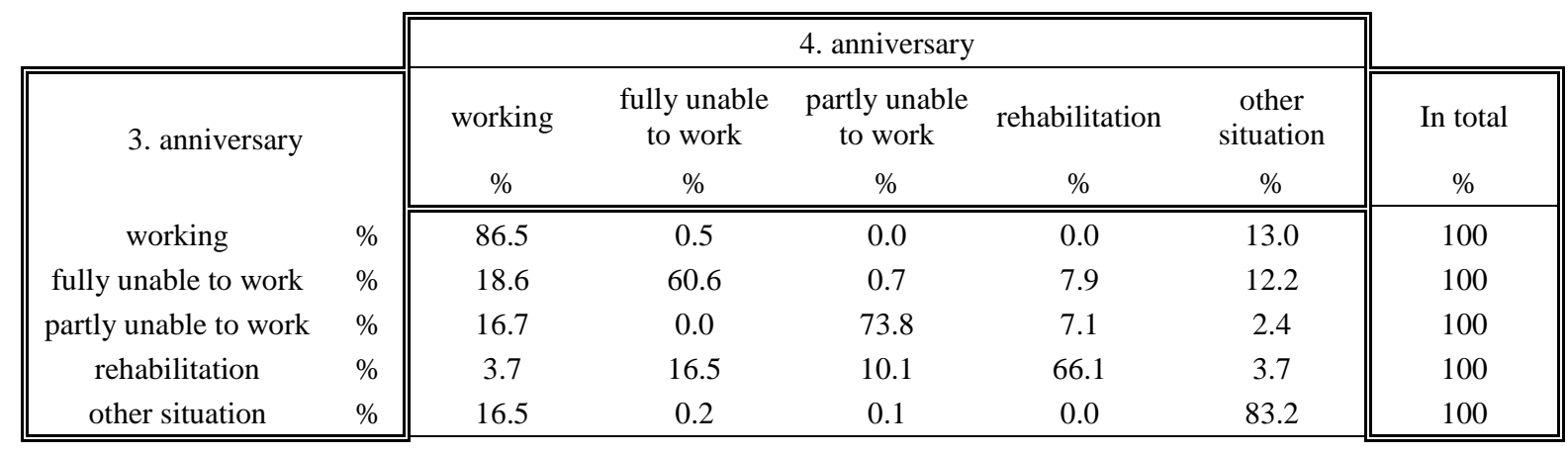

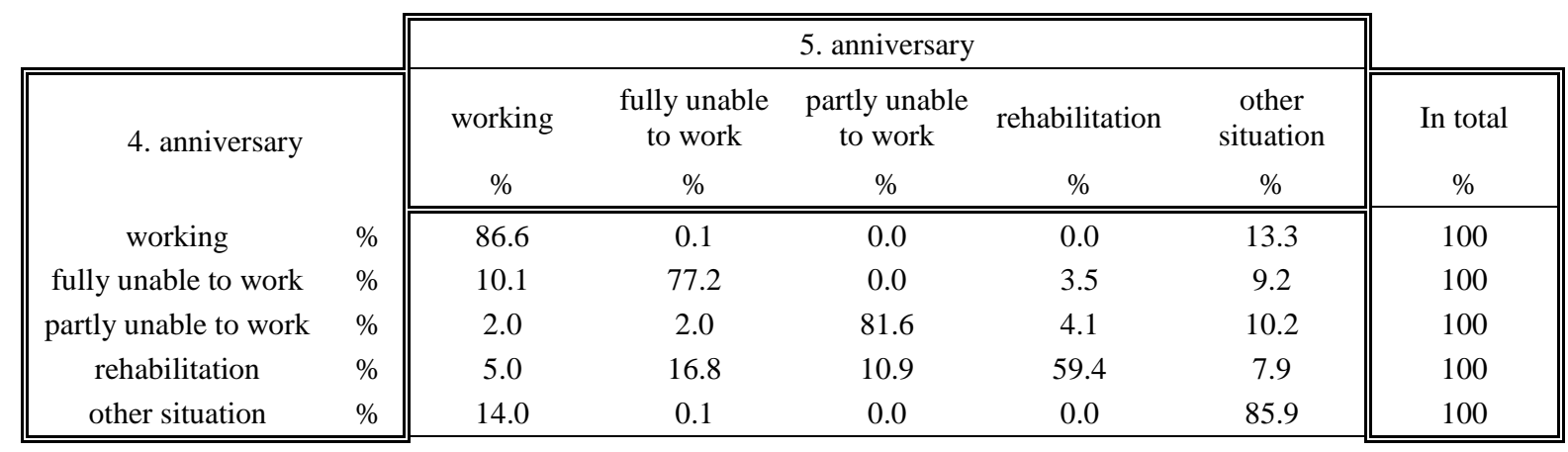


Table 3 Logistic regression of potential determinants of working after a severe occupational accident.

\begin{tabular}{|c|c|c|c|}
\hline & N (\%) & Odds ratio & $\begin{array}{c}95 \% \text { CI for } \\
\text { odds ratio }\end{array}$ \\
\hline \multicolumn{4}{|l|}{ Age*** } \\
\hline $14-34$ & $2728(24)$ & $3.24 * * *$ & $2.94-3.32$ \\
\hline $35-49$ & $4064(35)$ & $3.12 * * *$ & $3.01-3.48$ \\
\hline $50-68$ & $4793(41)$ & 1.00 & \\
\hline \multicolumn{4}{|l|}{ Gross annual income $(€)^{* * *}$} \\
\hline $0-10000$ & $926(8)$ & 1.00 & \\
\hline $10001-20000$ & $1204(10)$ & $1.18^{* *}$ & $1.05-1.32$ \\
\hline $20001-30000$ & $2550(22)$ & $1.78^{* * *}$ & $1.60-1.97$ \\
\hline $30001-40000$ & $3428(30)$ & $2.16^{* * *}$ & $1.95-2.40$ \\
\hline $40001-50000$ & $1767(15)$ & $2.44^{* * *}$ & $2.18-2.74$ \\
\hline $50001-60000$ & $715(6)$ & $2.24 * * *$ & $1.95-2.58$ \\
\hline $60001-$ & $519(5)$ & $2.45^{* * *}$ & $2.08-2.88$ \\
\hline \multicolumn{4}{|l|}{ Type of work*** } \\
\hline mining, quarrying and construction work & $1628(14)$ & 1.00 & \\
\hline manufacturing & $3465(30)$ & 1.04 & $0.95-1.13$ \\
\hline transportation and traffic work & $1132(10)$ & $1.24 * * *$ & $1.11-1.38$ \\
\hline agriculture, forestry and fishing & 367 (3) & 1.11 & $0.94-1.30$ \\
\hline student & $92(1)$ & 1.30 & $0.86-1.98$ \\
\hline service sector work & $1451(13)$ & $1.19 * * *$ & $1.08-1.32$ \\
\hline $\begin{array}{l}\text { technical, scientific, legal, } \\
\text { humanistic and artistic work }\end{array}$ & $681(6)$ & $1.42^{* * *}$ & $1.24-1.62$ \\
\hline commercial work & $463(4)$ & $1.35^{* * *}$ & $1.15-1.58$ \\
\hline administrative and office work & $991(9)$ & $1.25^{* * *}$ & $1.11-1.40$ \\
\hline health care and social work & $1315(11)$ & $1.37^{* * *}$ & $1.23-1.52$ \\
\hline \multicolumn{4}{|l|}{ Part of body injured $* * *$} \\
\hline neck & $135(1)$ & 1.00 & \\
\hline whole body or multiple locations & $568(5)$ & 1.20 & $0.92-1.58$ \\
\hline head & $205(2)$ & 1.00 & $0.74-1.37$ \\
\hline back & $491(4)$ & 1.15 & $0.88-1.51$ \\
\hline torso and organs & $465(4)$ & 1.29 & $0.98-1.71$ \\
\hline upper extremities & $5526(48)$ & $1.56^{* * *}$ & $1.22-1.99$ \\
\hline lower extremities & $4132(36)$ & $1.58 * * *$ & $1.24-2.02$ \\
\hline other parts of body & $17(0)$ & 0.99 & $0.51-1.93$ \\
\hline unspecified & $46(0)$ & & \\
\hline \multicolumn{4}{|l|}{ Type of injury* } \\
\hline concussion and internal injuries & $1394(12)$ & 1.00 & \\
\hline traumatic amputations (Loss of body parts) & $157(1)$ & 1.06 & $0.83-1.36$ \\
\hline multiple injuries & $137(1)$ & 1.10 & $0.84-1.45$ \\
\hline dislocations, sprains and strains & $4131(36)$ & 1.02 & $0.94-1.12$ \\
\hline wounds and superficial injuries & $1154(10)$ & $1.12 *$ & $1.00-1.25$ \\
\hline bone fractures & $4289(37)$ & $1.13^{* *}$ & $1.03-1.23$ \\
\hline other specified injuries & $211(2)$ & 1.11 & $0.90-1.36$ \\
\hline unspecified & $112(1)$ & & \\
\hline \multicolumn{4}{|l|}{ Previous situation in life ${ }^{* * *}$} \\
\hline fully unable to work (due to work accident) & 203-677 (2-6) & 1.00 & \\
\hline working & $\begin{array}{l}\text { 6803-8168 (59- } \\
71)\end{array}$ & $15.15^{* * *}$ & $13.06-17.57$ \\
\hline partly unable to work (due to work accident) & $23-52(0)$ & $0.52 * *$ & $0.33-0.83$ \\
\hline accident rehabilitation & $38-109(0-1)$ & $0.14^{* * *}$ & $0.09-0.22$ \\
\hline other situation & $\begin{array}{l}2702-4456(23- \\
39)\end{array}$ & 0.94 & $0.81-1.09$ \\
\hline $\mathrm{R}^{2}$ & & 0.419 & \\
\hline $\mathrm{N}$ & & 10984 & \\
\hline
\end{tabular}

